\title{
Effectiveness of Pentoxifylline in the treatment of oral submucous fibrosis patients: a case-control study
}

\author{
Annette M. Bhambal ${ }^{1 *} \mathbb{D}$, Ajay Bhambal ${ }^{1}$, U. S. Shukla ${ }^{2}$ and Aashna Dhingra ${ }^{1}$
}

\begin{abstract}
Background: Oral submucous fibrosis (OSMF) is a potentially malignant disorder largely seen in the South-Asian countries where areca nut is found to be the main predisposing factor. Pentoxifylline, a methylxanthine derivative, has vasodilating properties and is believed to increase the vascularity of the mucosal layer. This study was designed to determine the effect of pentoxifylline (Trental) on the clinical progression of oral submucous fibrosis. Aim: The present study was aimed to evaluate the effectiveness of drug pentoxifylline in the management of OSMF and to correlate the clinical parameters evaluated before and after treatment.

Methods: Study Design: This investigation was conducted as a case-control study incorporating a Control Group in comparison to a Study Group where pentoxifylline $400 \mathrm{mg}$ was administered 3 times daily, as coated, sustainedrelease tablets for prescribed for 3 months. The stipulated period for the study was 8 months and a total of 80 cases of oral submucous fibrosis ( 40 test subjects and 40 controls) were included in this study and $100 \%$ acquiescence was reported at the end of the test period.

Results: Mild dizziness and gastric irritation were the only untoward symptoms reported in 2 of the volunteers in the study group during this trial. These were managed by diet protocols. A review of the patients and controls was done at an interval of every 4 weeks for 3 months. The subjective and objective measurements were recorded. The follow-up data at each visit concerning each other and to base-line values were calibrated using nonparametric tests of the Chi-Square test and Mann-Whitney. Significant comparisons with regard to improvement were recorded as objective criteria of mouth opening ( $u$ value $=1.137, p=0.260$ ), tongue protrusion ( $u$ value $=0.262, p=0.794$ and cheek flexibility ( $u$ value $=0.990, p=0.326$ ). Subjective symptoms of burning sensation of mouth $(U$ value $=2.673$, $p=0.008$ ), pain on opening the mouth ( $U$ value $=4.320, p<0.0001)$, difficulty in swallowing and difficulty in the speech were also recorded.
\end{abstract}

Conclusion: This study showed the effectiveness of pentoxifylline as an additional therapy in the routine management of oral submucous fibrosis.

Keywords: Oral submucous fibrosis, Pentoxifylline, Treatment

\footnotetext{
*Correspondence: 11drann@gmail.com

'Department of Public Health Dentistry, People's College of Dental Sciences

and Research Centre, Bhopal, Madhya Pradesh, India

Full list of author information is available at the end of the article
}

(c) The Author(s). 2019 Open Access This article is distributed under the terms of the Creative Commons Attribution 4.0 International License (http://creativecommons.org/licenses/by/4.0/), which permits unrestricted use, distribution, and reproduction in any medium, provided you give appropriate credit to the original author(s) and the source, provide a link to the Creative Commons license, and indicate if changes were made. The Creative Commons Public Domain Dedication waiver (http://creativecommons.org/publicdomain/zero/1.0/) applies to the data made available in this article, unless otherwise stated. 


\section{Introduction}

Oral submucous fibrosis (OSF) remains the most common potentially malignant disorder largely seen in the south Asian countries and emigrants from these countries to other regions. It affects $0.2-0.5 \%$ of the Indian population.1 Evidence shows that the fibrogenic potential of areca nut alkaloids and tannin is the main cause of this disorder. The degree of vascularity of the diseased mucosa in OSF has always been an enigma. The atrophic epithelium is foreseen to pre-dispose to malignant transformation when brought in contact with oral carcinogens [1].

Pentoxifylline is a methylxanthine derivative that has vasodilating properties. It is believed to increase the vascularity of the mucosal layer. The objective of this clinical study was designed to determine the effect of pentoxifylline on the microvascularity and clinicopathological progression of oral submucous fibrosis [2].

This investigation was carried as a case-control study incorporating a control group (multi-vitamins) in comparison to the study group (pentoxifylline $400 \mathrm{mg}$ thrice daily) administered in the form of coated sustainedrelease tablets.

\section{Patients and methods}

\section{Study design and sample size}

This prospective case-control clinical study was conducted in Bhopal, Central India from January 2017 to August 2017. Before starting the study, ethical clearance was obtained from the institutional ethical committee.

This was a cross-sectional study where the sample size was calculated by using the following formula:

$n=\mathrm{t}^{2} \mathrm{x} \mathrm{p}(1-\mathrm{p})$ in which $n=$ required sample size.

$\mathrm{m}^{2} \mathrm{t}=$ confidence level at 95\% (standard value of 1.96).

$p=$ estimated prevalence of OSF in the project area.

$\mathrm{m}=$ margin of error at $5 \%$ (standard value of 0.05 ).

80 clinically diagnosed cases of OSF of either sex in the age range of 15 to 65 years were included in the study.

The inclusion criteria were as follows:

1. Patients with clinically diagnosed OSMF.

2. Patients who have not undergone any treatment for OSMF in past.

3. Patients who were willing to quit gutkha, areca nut and/or with tobacco chewing habit.

4. Patients who were ready to attend regular follow-ups.

The exclusion criteria were as follows:

1. Patients who have undergone any treatment for OSMF in past.
2. Those with any evidence of cardiac, gastrointestinal, kidney or metabolic disorders, pregnancy or lactation may interfere with the study protocol.

3. Patients with coexisting disease or disorder of the orofacial region other than OSMF which may interfere with the study protocol.

4. Patients with dysplastic features.

5. Patients with the inadequate reference point (i.e. incisal edges of the central incisors) for measuring interincisal distance.

Participants were explained about the disease and the medications. They were also advised to refrain from this deleterious habit before the commencement of the study. Written consent was obtained before participating in the study. Relevant information was documented in structured proforma. These OSF patients were selected by a simple random method and were staged by established clinical parameters proposed by Bailoor D et al., 2005 [3]. The volunteers of grades 1,2 and 3 were randomly allotted to the groups through a lottery method. Grades 4 and 5 were ruled out as they fell into the exclusion criteria. The patients were grouped into 2, the study or experimental drug group (EDG, $n=40$ ) who were treated with pentoxifylline, (Trental $400 \mathrm{mg}$ tablets) and the control or standard drug group (SDG, $n=40$ ) who were administered multi-vitamin capsules (B-complex one capsule before sleep daily). Clinical and hematological workup to rule out systemic ailments like hypertension, diabetes mellitus, cardiac diseases, gastroenterological disorders, and bleeding disorders was done.

Initially, a reduced dosage of pentoxifylline (i.e. $200 \mathrm{mg}$ thrice daily) was administered to all the patients in the EDG for the first 30 days. After 4 weeks serological tests were done to record any changes. The dose was then hiked to $400 \mathrm{mg}$ thrice daily for 2 more months. One patient complained of dizziness in the early stages of the study and was dropped out of the study. However, he was replaced with another patient to maintain the sample size. Thus the dropout figure recorded was zero. Clinical follow-up and review of all the patients included in the EDG and SDG were carried out at 30 days intervals for the whole trial period of 3 months. During each visit, recordings to evaluate the objective and subjective improvement from the disease of both the groups were assessed and scored and entered in a specially designed proforma charted for the purpose. The same investigator measured all the patients during each visit thus preventing bias.

\section{Study variables}

The clinical parameters were recorded as follows [3]:

- Improvement in mouth opening (measurement in millimeters of inter-incisal /alveolar clearance) 
- Relief from intolerance to spicy food/ relief from burning sensation (measured by Visual Analogue Scale)

- Pain on opening the mouth wide (measured by Visual Analogue Scale)

- Cheek flexibility

- Tongue protrusion (measurement in millimeters)

- Blanching, depapillation of tongue and extent of fibrous bands.

- Statistical comparison of EDG and SDG at each visit concerning each other and to base-line values (pretreatment measurements) was done using a non- parametric test or Mann Whitney test.

\section{Follow up period}

All the patients included in this clinical trial were followed up to 6 months after cessation of active medication.

\section{Results}

Assessment of disease progression was measured at an interval of 30 days for 12 weeks. The study comprised of 80 newly diagnosed cases of OSF who were randomly allocated into the 2 groups comprising of 40 each.

According to the grading system proposed by Bailoor D et al. in 2005 [3] and the criteria of the study, 21 patients were of grade I OSF of which 19 were males. 33 patients were of Grade II OSF of which 30 were males. 26 patients were of Grade III OSF, of which 19 were males (Table 1).

\section{Habits among OSF patients}

Paan masala with tobacco was the most common chewing habit among the patients with 6 in Grade I, 15 in grade II and 7 chewers in grade III OSF. Other smokeless forms of deleterious habits were zarda, paan with or without tobacco, areca nut only (processed or unprocessed) or pan masala without tobacco). Only 2 patients had OSMF without habits (Table 1).
Involvement of various anatomical sites in OSMF patients More than one anatomical site of the oral mucosa was either affected by blanching with or without fibrotic bands. Most of the patients had simultaneous involvement of multiple sites. Blanching was present in most of the cases (63) while 56 patients had fibrous bands (Table 2).

\section{Chewing habits among OSMF patients}

It was observed that most patients retained the quid in their oral cavity and then swallowed it after some time. The majority of the volunteers chewed about 6-10 quids/day with a maximum duration of about $10 \mathrm{~min}$ (Table 3).

\section{Intra and intergroup comparison of treatment response}

\section{Relief from burning sensation in OSF patients}

The intensity of the burning sensation was seen in all the patients and was measured by a visual analog scale (VAS). A comparison of improvement of the symptom was made at each visit between EDG and SDG. The comparisons were 'highly significant' at the end of the 3rd month $(p=0.008)$ (Tables 4 and 5).

\section{Relief from pain on opening the mouth in VAS}

A comparison of relief from pain on opening the mouth was made at each visit between study and control. The comparisons were 'highly significant' in all the visits (Tables 4 and 5).

\section{Improvement in mouth opening}

Inter-incisal / alveolar clearance recorded between the follow-up visits of study and control groups of patients concerning base-line values was analyzed using the test of Mann Whitney (Kruskal Wallis test). The comparisons made were not statistically significant (Tables 4 and 6).

Table 1 Etiologic factors in OSMF patients

\begin{tabular}{|c|c|c|c|c|c|c|}
\hline \multirow[t]{2}{*}{ ETIOLOGIC FACTOR } & \multicolumn{2}{|c|}{ OSMF Grade I } & \multicolumn{2}{|c|}{ OSMF Grade II } & \multicolumn{2}{|c|}{ OSMF Grade III } \\
\hline & Male & Female & Male & Female & Male & Female \\
\hline Tobacco with lime (Zarda) & 6 & 0 & 5 & 1 & 6 & 2 \\
\hline Paan with tobacco & 3 & 0 & 2 & 0 & 4 & 2 \\
\hline Paan without tobacco & 1 & 0 & 1 & 0 & 0 & 0 \\
\hline Plain areca nut Processed & 2 & 0 & 3 & 1 & 0 & 0 \\
\hline Plain areca nut Unprocessed & 0 & 0 & 3 & 0 & 3 & 1 \\
\hline Pan masala with tobacco (Gutkha) & 5 & 1 & 14 & 1 & 5 & 2 \\
\hline Pan masala without tobacco (Gutkha) & 1 & 0 & 2 & 0 & 1 & 0 \\
\hline No Habits & 1 & 1 & 0 & 0 & 0 & 0 \\
\hline
\end{tabular}


Table 2 Clinical examination of OSMF patients

\begin{tabular}{lll}
\hline $\begin{array}{l}\text { Anatomical Site(s) } \\
\text { Involved }\end{array}$ & $\begin{array}{l}\text { Blanching } \\
\text { No. of Cases }\end{array}$ & $\begin{array}{l}\text { Fibrous Bands } \\
\text { No. of Cases }\end{array}$ \\
\hline Buccal Mucosa & 63 & 56 \\
Tongue & 50 & 15 \\
Labial Mucosa & 53 & 24 \\
Floor of Mouth & 50 & 16 \\
Soft Palate & 57 & 43 \\
Pterygo-mandibular raphe & 59 & 44 \\
\hline
\end{tabular}

\section{Improvement in tongue protrusion}

The comparisons were unpredictable. When analyzed separately the test cases recorded better overall improvement when compared to control (Tables 4 and 6).

\section{Cheek flexibility}

Although individually the study group recorded improvement in the cheek flexibility, the results were not statistically significant. (Tables 4 and 6).

\section{Improvement from difficulty in swallowing and speech}

Although there was relief from fibrotic bands (peri-oral, anterior and posterior buccal mucosa, the junction of the hard and soft palate), the comparisons made were inconsistent and therefore rated as 'inconclusive'. (Tables 4 and 7).

Chi-square test/ Mann-Whitney test was used wherever appropriate.

\section{Discussion}

Oral submucous fibrosis leads to mucosal ischemia and resultant epithelial atrophy. A defective inflammatory reparative response culminating in fibrotic healing is the hallmark of the disorder. The degree of vascularity of the diseased mucosa in OSF has always been a matter of concern. It affects about $0.2-0.5 \%$ population of India [1]. The malignant transformation rate is $7.6 \%$ [1].

Paan masala with tobacco was the most common habit found in this study. Other smokeless forms of deleterious habits were zarda, areca nut only (processed or unprocessed) or pan masala without tobacco. (Table 1) Similar predisposing factors were seen in other studies [3-7].

Santosh Patil, Sneha Maheshwari (2014) 58\% of the patients had betel nut chewing habit, while $23 \%$ of the patients had tobacco chewing habit. $42 \%$ of the patients consumed spicy foods, which were among the main causative factors for OSMF in the study population [4].

Ravi Mehrotra, HP Singh, SC Gupta, M Singh, S Jain (2011) in their study found that $64 \%$ of the patients were in the habit of using pan masala or dohra (mixture of tobacco and slaked lime - sold locally), 20\% patients used pan masala or dohra with betel quid, $7 \%$ patients used betel quid with tobacco and $6 \%$ were smokers. Those who chewed areca nut in any form were habituated to 1 to 20 chews per day, (median 6.0) for a period of 1 to 25 years (median 6 years) [5].

Fareedi Mukram Ali et. al. (2013) stated that gutkha-chewing habit alone was identified in 58 subjects and those associated with gutkha and tobacco were 33

Table 3 Chewing habits among the OSF patients

\begin{tabular}{|c|c|c|c|}
\hline CHEWING HABIT & GRADE I OSMF & GRADE \| OSMF & GRADE III OSMF \\
\hline \multicolumn{4}{|l|}{ STYLE OF CHEWING } \\
\hline Does not Chew & 2 & 0 & 0 \\
\hline Spits the quid & 8 & 4 & 0 \\
\hline Swallows the quid & 1 & 5 & 1 \\
\hline Retains in the mouth and then spits & 6 & 15 & 12 \\
\hline Retains in the mouth and then swallows & 4 & 9 & 13 \\
\hline \multicolumn{4}{|l|}{ FREQUENCY OF CHEWING } \\
\hline 0 quids /day & 2 & 0 & 0 \\
\hline $1-2$ quids per day & 10 & 3 & 0 \\
\hline 2-5/day & 5 & 8 & 4 \\
\hline 6-10/day & 3 & 15 & 16 \\
\hline 11-15/day & 1 & 5 & 4 \\
\hline$>$ 15/day & 0 & 2 & 2 \\
\hline \multicolumn{4}{|l|}{ DURATION OF CHEWING } \\
\hline Upto 2 min & 10 & 6 & 0 \\
\hline Upto 5 min & 8 & 14 & 2 \\
\hline Upto $10 \mathrm{~min}$ & 3 & 11 & 11 \\
\hline More than $10 \mathrm{~min}$ & 0 & 2 & 13 \\
\hline
\end{tabular}


Table 4 Symptoms among the OSF patients

\begin{tabular}{llll}
\hline SYMPTOMS & OSMF Grade I & OSMF Grade II & OSMF Grade III \\
& No. of subjects & No. of subjects & No. of subjects \\
\hline Burning sensation & 21 & 33 & 26 \\
Pain & 4 & 21 & 25 \\
Restricted Mouth Opening & 0 & 33 & 26 \\
Tongue protrusion & 0 & 10 & 20 \\
Cheek flexibility & 0 & 19 & 26 \\
\hline
\end{tabular}

with a mean age of 28.2 years and 32.3 years, respectively. The number of people getting affected with OSMF was more associated with gutkha and areca nut with the $P$-value of the analysis ranging from 0.05 to 0.01 [6].

In our study blanching and fibrotic bands were present on the buccal mucosa and pterygomandibular raphe in most of the cases followed by the soft palate, labial mucosa, floor of the mouth and tongue in descending order. (Table 2). The data was similar to clinical studies reported in the literature [7]. In the EDG, the burning sensation and pain reduced significantly by the end of the treatment when compared to SDG. The reduction in the burning sensation and pain was significant in the 2nd week itself. (Table 5). Mouth opening significantly increased by 1.137 ( $\mathrm{U}$ value).The increase was significant from the first month of the treatment (Table 6). Tongue protrusion and cheek flexibility increased accordingly in EDG. Thus though there was a significant improvement in all criteria evaluated for the disease, there was no significant difference in treatment response when compared to the increase in severity of the disease. (Tables 5, 6 and 7).

R Rajendran, Vidya Rani, Saleem Shaikh (2006) in their study reported that clinical improvements in mouth opening, tongue protrusion, difficulty in speech

Table 5 Distribution of burning sensation, pain on opening according to groups in different time periods

\begin{tabular}{|c|c|c|c|c|c|c|c|}
\hline SYMPTOMS & & Group & $\mathrm{N}$ & Mean Rank & Sum of Ranks & $U$ value & $P$ value \\
\hline \multirow[t]{14}{*}{ BURNING SENSATION } & \multirow[t]{3}{*}{ Baseline } & Pentoxyfylline & 40 & 33.97 & 1087.00 & & \\
\hline & & Placebo & 40 & 31.03 & 993.00 & 0.641 & 0.521 \\
\hline & & Total & 80 & & & & \\
\hline & \multirow[t]{3}{*}{ 1st Month } & Pentoxyfylline & 40 & 30.34 & 971.00 & & \\
\hline & & Placebo & 40 & 34.66 & 1109.00 & 0.955 & 0.340 \\
\hline & & Total & 80 & & & & \\
\hline & \multirow[t]{3}{*}{ 2nd Month } & Pentoxyfylline & 40 & 27.98 & 895.50 & & \\
\hline & & Placebo & 40 & 37.02 & 1184.50 & 2.073 & $0.038^{*}$ \\
\hline & & Total & 80 & & & & \\
\hline & \multirow[t]{3}{*}{ 3rd Month } & Pentoxyfylline & 40 & 26.94 & 862.00 & & \\
\hline & & Placebo & 40 & 38.06 & 1218.00 & 2.673 & $0.008^{*}$ \\
\hline & & Total & 80 & & & & \\
\hline & \multirow[t]{2}{*}{ Baseline } & Pentoxyfylline & 40 & 29.78 & 953.00 & & \\
\hline & & Placebo & 40 & 35.22 & 1127.00 & 1.180 & 0.238 \\
\hline \multirow[t]{10}{*}{ PAIN ON OPENING THE MOUTH } & & Total & 80 & & & & \\
\hline & \multirow[t]{3}{*}{ 1st Month } & Pentoxyfylline & 40 & 27.73 & 887.50 & & \\
\hline & & Placebo & 40 & 37.27 & 1192.50 & 2.103 & $0.035^{*}$ \\
\hline & & Total & 80 & & & & \\
\hline & \multirow[t]{3}{*}{ 2nd Month } & Pentoxyfylline & 40 & 23.58 & 754.50 & & \\
\hline & & Placebo & 40 & 41.42 & 1325.50 & 3.927 & $<0.0001^{*}$ \\
\hline & & Total & 80 & & & & \\
\hline & \multirow[t]{3}{*}{ 3rd Month } & Pentoxyfylline & 40 & 22.66 & 725.00 & & \\
\hline & & Placebo & 40 & 42.34 & 1355.00 & 4.320 & $<0.0001^{*}$ \\
\hline & & Total & 80 & & & & \\
\hline
\end{tabular}


Table 6 Distribution of mouth opening, tongue protrusion, cheek flexibility according to group in different time periods

\begin{tabular}{|c|c|c|c|c|c|c|c|}
\hline CLINICAL EXAMINATION & & Group & $\mathrm{N}$ & Mean & Std. Deviation & $U$ value & $P$ value \\
\hline \multirow[t]{8}{*}{ MOUTH OPENING (mm) } & Baseline & Pentoxyfylline & 40 & 26.7906 & 7.85162 & & \\
\hline & & Placebo & 40 & 25.7500 & 7.93116 & 0.527 & 0.600 \\
\hline & 1st Month & Pentoxyfylline & 40 & 27.8563 & 7.69147 & & \\
\hline & & Placebo & 40 & 26.7188 & 7.34950 & 0.605 & 0.547 \\
\hline & 2nd Month & Pentoxyfylline & 40 & 28.4484 & 7.82333 & & \\
\hline & & Placebo & 40 & 26.9375 & 7.35258 & 0.796 & 0.429 \\
\hline & 3rd Month & Pentoxyfylline & 40 & 29.1313 & 7.87435 & & \\
\hline & & Placebo & 40 & 26.9688 & 7.32862 & 1.137 & 0.260 \\
\hline \multirow[t]{9}{*}{ TONGUE PROTRUSION } & Baseline & Pentoxyfylline & 40 & 31.2813 & 8.48997 & & \\
\hline & & Placebo & 40 & 31.0313 & 9.62686 & 0.110 & 0.913 \\
\hline & 1st Month & Pentoxyfylline & 40 & 33.1250 & 8.71317 & & \\
\hline & & Placebo & 40 & 32.6250 & 9.95717 & 0.214 & 0.831 \\
\hline & 2nd Month & Pentoxyfylline & 40 & 34.3750 & 8.85274 & & \\
\hline & & Placebo & 40 & 33.7813 & 10.16869 & 0.249 & 0.804 \\
\hline & 3rd Month & Pentoxyfylline & 40 & 34.7500 & 8.90451 & & \\
\hline & & Placebo & 40 & 34.1250 & 10.11785 & 0.262 & 0.794 \\
\hline & Baseline & Pentoxyfylline & 40 & .8856 & .18243 & & \\
\hline \multirow[t]{7}{*}{ CHEEK FLEXIBILITY } & & Placebo & 40 & .9348 & .22551 & 0.958 & 0.342 \\
\hline & 1st Month & Pentoxyfylline & 40 & .9135 & .18642 & & \\
\hline & & Placebo & 40 & .9401 & .22707 & 0.511 & 0.611 \\
\hline & 2nd Month & Pentoxyfylline & 40 & .9144 & .19621 & & \\
\hline & & Placebo & 40 & .9441 & .22840 & 0.557 & 0.579 \\
\hline & 3rd Month & Pentoxyfylline & 40 & 3.8575 & 16.63277 & & \\
\hline & & Placebo & 40 & .9467 & .22938 & 0.990 & 0.326 \\
\hline
\end{tabular}

and swallowing, pain associated with the lesion and burning sensation were significant in the experimental group $(P<0.05)[8]$.

Prabhu N, Rao SS, Kotrashetti SM, Baliga SD, Hallikerimath SR, Angadi PV and Issrani R (2015) in their study randomly categorized thirty clinically confirmed OSF patients into group I and group II. In group I, pentoxifylline was administered as an adjunct along with other conventional therapies while the latter was advised conventional therapies only. Pre- and post-treatment of the burning sensation of mucosa were assessed. Both groups showed significant improvement [9].

J Liu, F Chen, Z Wei, M Qiu, Z Li, H Dan, Q Chen and $L$ Jiang (2018) in meta-analysis evaluating the efficacy of pentoxifylline in the treatment of oral submucous fibrosis, stated that pentoxifylline improved the subjective symptom of burning sensation (WMD:0.11, 95\% Ci: $-0.77,-.05 ; p<0.05)[10]$.

In a randomized clinical trial done by Chaithra Kalkur, Atul P. Sattur, Kruthika S. Guttal \& Anusha R. Lakshman (2019) on 50 cases of OSMF, of which the control group was on antioxidant therapy and the test cases were on pentoxifylline treatment. The values for the burning sensation of the mouth using the VAS was recorded. A significant reduction in burning sensation was seen in the pentoxifylline group when compared to the control group [11].

Pentoxifylline is a tri-substituted methylxanthine derivative. It has also been labeled as a "rheologic modifier" as it improves microcirculation of blood by increasing red cell deformability, leukocyte chemotaxis, antithrombin and antiplasmin activities, and fibrinolytic activity. This leads to a decrease in the red cell and platelet aggregation, granulocyte adhesion, fibrinogen levels, and whole blood viscosity [12]. Recent studies have described pentoxifylline's ability to decrease the production of tumor necrosis factor $\alpha$ and reduce some of the systemic toxicities mediated by interleukin-2 [4]. These two cytokines are important mediators of the inflammatory response. Also, this drug has been shown to increase the production of PGE2 and PGI2 by vascular epithelium, important in maintaining cellular integrity and homeostasis after acute injury [6].

Some studies have stated the efficacy of pentoxifylline in treating intermittent claudication caused by chronic peripheral arterial occlusion. These reports lead us to 
Table 7 Distribution of difficulty in swallowing, difficulty in speech, cheek flexibility according to group in different time periods

\begin{tabular}{|c|c|c|c|c|c|c|c|}
\hline & & Group & $\mathrm{N}$ & Mean Rank & Sum of Ranks & $U$ value & $P$ value \\
\hline \multirow[t]{16}{*}{ DIFFICULTY IN SWALLOWING } & Baseline & Pentoxyfylline & 40 & 32.50 & 1040.00 & & \\
\hline & & Placebo & 40 & 32.50 & 1040.00 & 0.000 & 1.000 \\
\hline & & Total & 80 & & & & \\
\hline & 1st Month & Pentoxyfylline & 40 & 32.00 & 1024.00 & & \\
\hline & & Placebo & 40 & 33.00 & 1056.00 & 0.587 & 0.558 \\
\hline & & Total & 80 & & & & \\
\hline & 2nd Month & Pentoxyfylline & 40 & 32.00 & 1024.00 & & \\
\hline & & Placebo & 40 & 33.00 & 1056.00 & 0.587 & 0.558 \\
\hline & & Total & 80 & & & & \\
\hline & 3rd Month & Pentoxyfylline & 40 & 32.00 & 1024.00 & & \\
\hline & & Placebo & 40 & 33.00 & 1056.00 & 0.587 & 0.558 \\
\hline & & Total & 80 & & & & \\
\hline & Baseline & Pentoxyfylline & 40 & 32.50 & 1040.00 & & \\
\hline & & Placebo & 40 & 32.50 & 1040.00 & 0.000 & 1.000 \\
\hline & & Total & 80 & & & & \\
\hline & 1st Month & Pentoxyfylline & 40 & 32.50 & 1040.00 & & \\
\hline \multirow[t]{8}{*}{ DIFFICULTY IN SPEECH } & & Placebo & 40 & 32.50 & 1040.00 & 0.000 & 1.000 \\
\hline & & Total & 80 & & & & \\
\hline & 2nd Month & Pentoxyfylline & 40 & 32.50 & 1040.00 & & \\
\hline & & Placebo & 40 & 32.50 & 1040.00 & 0.000 & 1.000 \\
\hline & & Total & 80 & & & & \\
\hline & 3rd Month & Pentoxyfylline & 40 & 32.50 & 1040.00 & & \\
\hline & & Placebo & 40 & 32.50 & 1040.00 & 0.000 & 1.000 \\
\hline & & Total & 80 & & & & \\
\hline
\end{tabular}

evaluate the role of peripheral vasodilator pentoxifylline, in the treatment of OSF, an oral potentially malignant disorder [7].

Berman and Duncan (1989) showed that fibroblasts cultured in the presence of pentoxifylline produce twice as much collagenase activity and decreased the amount of collagen, glycosaminoglycans, and fibronectins [13]. IL-1 induced fibroblast proliferation was inhibited by the addition of pentoxifylline. Berman et al (1992) stated that pentoxifylline blocked TNF- $\alpha$ induced synthesis of fibroblast collagen, glycosaminoglycans, and collagenolytic activity [14]. It was determined that these selective inhibitory effects occurred without altering TNF-a receptor mRNA, the number of cell receptors or affinity for TNF-a receptors compared with untreated controls. These results suggest that the inhibitory activities of pentoxifylline on fibroblasts are mediated at a locus other than TNF-a receptors [15]. Rajendran $\mathbf{R}$ et al (2006) used pentoxifylline as an adjunct in the treatment of OSMF for 7 months. After a 6-12 month follow-up, he reported significant improvement in subjective symptoms, of intolerance to spices and burning sensation of the mouth, in the experimental group as compared to patients in the control group $(P<0.01)$ [8]. However, Fedorowicz Z. et al (2008) reviewed the trial and stated that since the patients also received local heat therapy and underwent forceful mouth stretching exercises, it was not clear if the improvement was due to the drug or to associated heat therapy and stretching exercises. They also stated that these parameters were poorly defined as they were not based on any recognized and validated pain scale [16]. Ravi Mehrotra et al. (2011) studied the burning sensation in 62 clinically diagnosed cases of OSMF. 30 patients were given placebo (multivitamin) therapy and 32 patients were given Tab. Pentoxifylline $400 \mathrm{mg}$ for 7 months. Pentoxifylline was administered as an inductive regime for the initial 30 days at a reduced dosage of 2 tablets daily and then the dose was hiked to 3 tablets daily for 6 more months. The progress in the cessation of habit was monitored as the trial progressed when the patients came for follow-up. The response to treatment was evaluated every month. Subjective improvement in a burning sensation in the mouth was observed i.e. $39.4 \%$ in the placebo group and $86.6 \%$ in the pentoxifylline group [4]. The new adjunct in the treatment of oral submucous evaluated and reduction in burning sensation was similar to that of our 
study but at the same time, the improvement on the mouth opening was not so good. Bhavana Sujana Mulk, Prasanna Srinivas Deshpande, Nagalakshmi Velpula, Vani Chappidi, Raja Lakshmi Chintamaneni, Stuti Goyal (2013) in their study reported that the mean value for burning sensation before the treatment was 6.95 and after treatment was 1.55 with the $p$-value was $p<0.001$ [17].

The variability in the baseline of these parameters may be the reason for such variation in the results of all the studies.

It was observed that factors like the grade of the disease, habit frequency, and duration in these studies cannot be directly compared for factors like the mean age of participants. Habit frequency and duration, the grade of the disease, choice of drug, frequency, and stages of treatment all influence the final treatment outcome.

In our study, although both the groups showed improvement in burning sensation, pain, tongue protrusion, and cheek flexibility, there was no significant difference between the two groups when compared on basis of mouth opening, EDG showed better response in burning sensation as the improvement was significant form 5th week onwards, which was not in cases of SDG group. Better and faster improvement of pain on opening the mouth was achieved in EDG as against SDG.

The finding of the present study was in agreement with a similar study done by Rajendran $\mathbf{R}$ et al (2006) pentoxifylline $400 \mathrm{mg}$ three times daily, which resulted in improvement in mouth opening, tongue protrusion, and relief from perioral fibrotic bands. Improvement in subjective symptoms of intolerance to spices, burning sensation of the mouth, tinnitus, difficulty in swallowing and difficulty in the speech were also recorded at the end of the trial period [8]. In a similar study done by Bhavana Sujana Mulk et. al (2013) where pentoxifylline group showed statistically significant results $(p=$ 0.000 ) in all the three parameters namely mouth opening, burning sensation and tongue protrusion. On comparing both the drugs statistically insignificant results were obtained for mouth opening $(p=0.35)$ and tongue protrusion $(p=0.25)$ but statistically significant difference was seen in subjective parameter i.e. burning sensation $(p=0.04)$ [17].

Thus pentoxifylline was found to a superior drug in comparison to multivitamin alone in many aspects for the treatment of this condition. Most side effects caused by pentoxifylline involve the gastrointestinal tract and central nervous system [9]. Approximately 1\% report bloating, flatus, bleeding, dizziness, and headache. Both the central nervous system and gastrointestinal side effects are dose-related and are therefore minimized by dose reduction [9]. Although primary or adjunctive therapy with pentoxifylline has been suggested for a multitude of disorders that include cases of pathological fibrosis, there are few controlled clinical trials to confirm its efficacy. It is hoped that future double-blind placebo-controlled clinical studies that use pentoxifylline and its derivatives will determine if the many beneficial pharmacokinetic properties of pentoxifylline are effective in treating oral submucous fibrosis [18].

The comparison of results of different studies concluded pentoxifylline to be superior in terms of improvement in burning sensation, mouth opening, and tongue protrusion. Thus, the present research states that pentoxifylline is a better and safer substitute for corticosteroids and intralesional injections.

\section{Conclusion}

Oral submucous fibrosis (OSMF) is a potentially malignant oral epithelial lesion largely seen in the south Asian countries. Deranged collagen metabolism is believed to be the underlying pathophysiology.

Pentoxifylline, a methylxanthine derivative, has vasodilating properties and is believed to increase the vascularity of the mucosal layer. This study was designed to determine the effect of pentoxifylline (Trental) on the clinical progression of oral submucous fibrosis. Thus the present study was aimed to evaluate the effectiveness of drug pentoxifylline in the management of OSMF and to compare the clinical parameters evaluated before and after treatment. The patients were divided into 2 groups ( 40 test subjects and 40 controls). They were administered a multivitamin or pentoxifylline for 3 months. Treatment outcome was evaluated to measure patient reported changes in pain, burning, mouth opening, cheek flexibility and protrusion of the tongue, before and after treatment. There was a significant improvement in the disease condition in both groups. Though better and faster improvement in tongue protrusion and cheek flexibility was achieved in the pentoxifylline group, there was a significant difference between the two groups when compared on basis of mouth opening, burning sensation and pain. Thus, pentoxifylline was found to be a superior drug in comparison to the multivitamin drug. Adverse effects like mild dizziness gastrointestinal side effects were dose-related and are therefore minimized by dose reduction [18].

Significant comparisons with regard to improvement were recorded as objective measures of mouth opening $(\mathrm{u}$ value $=1.137, p=0.260)$, tongue protrusion $(\mathrm{u}$ value $=$ $0.262, p=0.794$ and cheek flexibility (u value $=0.990$, $p=0.326$ ). Subjective symptoms of burning sensation of mouth ( $\mathrm{U}$ value $=2.673, p=0.008$ ), pain on opening the mouth ( $\mathrm{U}$ value $=4.320, p<0.0001)$, difficulty in swallowing and difficulty in the speech were also recorded. This study showed the effectiveness of pentoxifylline as an additional therapy in the routine management of oral submucous fibrosis. 


\section{Acknowledgments}

Not applicable.

\section{Authors' contributions}

All authors read and approved the final manuscript

\section{Funding}

The work was self-funded.

\section{Availability of data and materials}

Datasets used and/or analyzed in the current study are available from the corresponding author on reasonable request.

\section{Ethics approval and consent to participate}

Institutional Ethics Committee (DCGl registration no. ecr/575/inst/MP/2014), Project Code: 2015 ORM05).

\section{Consent for publication}

Not applicable.

\section{Competing interests}

The authors declare that they have no competing interests.

\section{Author details}

'Department of Public Health Dentistry, People's College of Dental Sciences and Research Centre, Bhopal, Madhya Pradesh, India. ${ }^{2}$ Department of Community Medicine, Government Jhalawar Medical College, Jhalawar, Rajasthan, India.

Received: 17 July 2019 Accepted: 11 October 2019

Published online: 05 December 2019

\section{References}

1. Gupta J, Srinivasan SV, Daniel MJ. Efficacy of betamethasone, placental extract and Hyaluronidase in the treatment of OSMF: a comparative study. E-Journal of Dentistry. 2012;2:132-5.

2. Aara A, Satishkumar GP, Vani C, Venkat Reddy M, Sreekanth K, Ibrahim M. Comparative study of Intralesional dexamethasone, Hyaluronidase and Oral Pentoxifylline in patients with Oral submucous fibrosis. Global J Med Res. 2012;12(7):169-73.

3. Bailoor D, John A, Koteeshwaran D, Parekh BP, White lesions of oral mucosa. In: Bailoor D, Nagesh KS, editors. Fundamentals of oral medicine and radiology. 1st ed. New Delhi: Jaypee Brothers Medical Publishers (P) Itd; 2005. p. 117-33.

4. Mehrotra R, Singh HP, Gupta SC, Singh M, Jain S. Pentoxifylline therapy in the management of oral submucous fibrosis. Asian Pac J Cancer Prev. 2011;12:971-4.

5. Ali FM, et al. Oral submucous fibrosis: comparing clinical grading with duration and frequency of habit among areca nut and its products chewers. J Cancer Res Ther. 2013;9(3):471-6.

6. Patil S, Maheshwari S. Efficacy of pentoxifylline in the management of oral submucous fibrosis. Journal of Orofacial. Sciences. 2014;6(2):94-98.

7. Rajendran R, Vijayakumar T, Vasudevan DM. An alternative pathogenetic pathway for oral submucous fibrosis. Med Hypothesis. 1989;30:35-7.

8. Rajendran R, Rani V, Shaikh S. (2006). Pentoxifylline therapy: a new adjunct in the treatment of oral submucous fibrosis. Indian J of Dent Res. 2006;17(4):190-8.

9. Prabhu N, Rao SS, Kotrashetti SM, Baliga SD, Hallikerimath SR, Angadi PV, Issrani R. (2015). Pentoxifylline in patients with oral submucous fibrosis-a randomized clinical trial. J. Maxillofac. Oral Surg. 2015;14(1):81-9.

10. Liu J, Chen F, Wei Z, Qiu M, Li Z, Dan H, Chen Q, Jiang L. Evaluating the efficacy of pentoxifylline in the treatment of oral submucous fibrosis: a meta-analysis. Oral Diseases 2018. 2018;24(5):706-16.

11. Kalkur C, Sattur AP, Guttal KS, Lakshman AR. "Introducing modified Dakkak and Bennett grading system for Indian food in Oral submucous fibrosis": a Dharwad study. J Diet Suppl. 2019;16(2):207-14.

12. Ward A, Clissold SP. Pentoxifylline: a review of its pharmacodynamic and pharmacokinetic properties and its therapeutic efficacy. Drug Eval. 1987;34:50-97.

13. Berman B, Dunken MR. Pentoxifylline inhibits normal human dermal fibroblast in vitro proliferation, collagen, glycosaminoglycans, and fibronectin production, and increases collagenase activity. J Invest Dermatol. 1989:92:605-10.

14. Berman B, Wietzerbin J, Sangean J, et al. Pentoxifylline inhibits certain constitutive and tumor necrosis factor-a induced activities of human normal dermal fibroblasts. J Invest Dermatol. 1992;98:706-12.

15. Edwards MJ, Abney DL, Miller FN. Pentoxifylline inhibits interleukin-2 induced leukocyte-endothelial adherence and reduces systemic toxicity. Surg. 1991;110:199-204.

16. Fedorowicz Z. Chan Shih- yen E, Dorri M, Nasser M, Newton T, Shi L. (2008) interventions for the management of oral submucous fibrosis. Cochrane Database Syst Rev. 2008:4:CD007156.

17. Mulk BS, Deshpande PS, Velpula N, Chappidi V, Chintamaneni RL, Goyal S. (2013). Spirulina and pentoxyfilline- a novel approach for treatment of oral submucous fibrosis. J Clin Diagn Res. 2013;7(12):3048-50.

18. Awadallah M, Idle M, Patel K, Kademani D. Management update of potentially premalignant Oral epithelial lesions. Oral Surg Oral Med Oral Pathol Oral Radiol. 2018:125:628-36.

\section{Publisher's Note}

Springer Nature remains neutral with regard to jurisdictional claims in published maps and institutional affiliations.

\section{Ready to submit your research? Choose BMC and benefit from:}

- fast, convenient online submission

- thorough peer review by experienced researchers in your field

- rapid publication on acceptance

- support for research data, including large and complex data types

- gold Open Access which fosters wider collaboration and increased citations

- maximum visibility for your research: over $100 \mathrm{M}$ website views per year

At $\mathrm{BMC}$, research is always in progress.

Learn more biomedcentral.com/submissions 